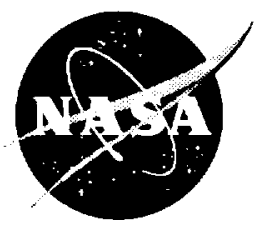

\title{
Satellite Communications Using Commercial Protocols
}

William D. Ivancic and James H. Griner

Glenn Research Center, Cleveland, Ohio

Robert Dimond and Brian D. Frantz

BBN Technologies, Cambridge, Massachusetts

Brian Kachmar

Analex Corporation, Brook Park, Ohio

Dan Shell

Cisco Systems, Incorporated, San Jose, California 
Since its founding, NASA has been dedicated to the advancement of aeronautics and space science. The NASA Scientific and Technical Information (STI) Program Office plays a key part in helping NASA maintain this important role.

The NASA STI Program Office is operated by Langley Research Center, the Lead Center for NASA's scientific and technical information. The NASA STI Program Office provides access to the NASA STI Database, the largest collection of aeronautical and space science STI in the world. The Program Office is also NASA's institutional mechanism for disseminating the results of its research and development activities. These results are published by NASA in the NASA STI Report Series, which includes the following report types:

- TECHNICAL PUBLICATION. Reports of completed research or a major significant phase of research that present the results of NASA programs and include extensive data or theoretical analysis. Includes compilations of significant scientific and technical data and information deemed to be of continuing reference value. NASA's counterpart of peerreviewed formal professional papers but has less stringent limitations on manuscript length and extent of graphic presentations.

- TECHNICAL MEMORANDUM. Scientific and technical findings that are preliminary or of specialized interest, e.g., quick release reports, working papers, and bibliographies that contain minimal annotation. Does not contain extensive analysis.

- CONTRACTOR REPORT. Scientific and technical findings by NASA-sponsored contractors and grantees.
- CONFERENCE PUBLICATION. Collected papers from scientific and technical conferences, symposia, seminars, or other meetings sponsored or cosponsored by NASA.

- SPECIAL PUBLICATION. Scientific, technical, or historical information from NASA programs, projects, and missions, often concerned with subjects having substantial public interest.

- TECHNICAL TRANSLATION. Englishlanguage translations of foreign scientific and technical material pertinent to NASA's mission.

Specialized services that complement the STI Program Office's diverse offerings include creating custom thesauri, building customized data bases, organizing and publishing research results ... even providing videos.

For more information about the NASA STI Program Office, see the following:

- Access the NASA STI Program Home Page at http://www.sti.nasa.gov

- E-mail your question via the Internet to help@sti.nasa.gov

- Fax your question to the NASA Access Help Desk at (301) 621-0134

- Telephone the NASA Access Help Desk at (301) 621-0390

- Write to:

NASA Access Help Desk

NASA Center for AeroSpace Information 7121 Standard Drive Hanover, MD 21076 


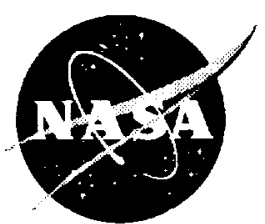

\section{Satellite Communications Using Commercial Protocols}

William D. Ivancic and James H. Griner

Glenn Research Center, Cleveland, Ohio

Robert Dimond and Brian D. Frantz

BBN Technologies, Cambridge, Massachusetts

Brian Kachmar

Analex Corporation, Brook Park, Ohio

Dan Shell

Cisco Systems, Incorporated, San Jose, California

Prepared for the

18th International Communication Satellite Systems Conference

sponsored by the American Institute of Aeronautics and Astronautics

Oakland, California, April 10-14, 2000

National Aeronautics and

Space Administration

Glenn Research Center 
Trade names or manufacturers' names are used in this report for identification only. This usage does not constitute an official endorsement, either expressed or implied, by the National Aeronautics and Space Administration.

Available from

NASA Center for Aerospace Information 7121 Standard Drive

Hanover, MD 21076

Price Code: A03

National Technical Information Service 5285 Port Royal Road Springfield, VA 22100 Price Code: A03 


\title{
SATELLITE COMMUNICATIONS USING COMMERCIAL PROTOCOLS
}

\author{
William D. Ivancic and James $\mathrm{H}$. Griner \\ National Aeronautics and Space Administration \\ Glenn Research Center \\ Cleveland, Ohio 44135 \\ Robert Dimond and Brian D. Frantz \\ GTE Internetworking \\ BBN Technologies \\ 10 Moulton Street \\ Cambridge, Massachusetts 02138 \\ Brian Kachmar \\ Analex Corporation \\ 3001 Aerospace Parkway \\ Brook Park, Ohio 44142 \\ Dan Shell \\ Cisco Systems, Incorporated \\ 170 West Tasman Drive \\ San Jose, California 95134
}

\begin{abstract}
NASA Glenn Research Center has been working with industry, academia, and other government agencies in assessing commercial communications protocols for satellite and space-based applications. In addition, NASA Glenn has been developing and advocating new satellite friendly modifications to existing communications protocol standards. This paper summarizes recent research into the applicability of various commercial standard protocols for use over satellite and space-based communications networks as well as expectations for future protocol development. It serves as a reference point from which the detailed work can be readily accessed. Areas that will be addressed include asynchronous-transfer-mode quality of service; completed and ongoing work of the Internet Engineering Task Force; data-link-layer protocol development for unidirectional link routing; and protocols for aeronautical applications, including mobile Internet protocol routing for wireless/mobile hosts and the aeronautical telecommunications network protocol.
\end{abstract}

\section{ACTS CAPABILITIES}

The Advanced Communications Technology Satellite (ACTS) has been heavily used for protocol research. It provides a unique platform with its Ka-band capabilities, onboard switching and routing, matrix switching, spot beams, and wide-bandwidth channels. All aspects of ACTS were used for our research. The onboard processing channels were used to provide $1.544-\mathrm{Mbps}$ (T1) connections for transport control protocol (TCP) and hypotext transfer protocol (HTTP) research. The $800-\mathrm{MHz}$ bandwidth channels have been used to stress TCP implementations at optical carrier (OC) 12 $(622 \mathrm{Mbps})$ rates. $\mathrm{Ka}$-band also enables use of ultra-smallaperture terminals for protocol research, such as bandwidth on demand. It is anticipated that ACTS will be used for much aeronautics communications research.

\section{ATM RESEARCH}

Asynchronous transfer mode (ATM) is an important communications technology for satellites. ATM was designed for multimedia applications and allows for ease of switching, control of service quality, and control of jitter. However, ATM was designed for near-error-free links, such as fiber optics. ATM and ATM-like technologies (cell switching) are of great interest to the satellite industry for onboard switching and routing. Cell-based switching maps well into satellite network access techniques, such as multiple-frequency, time-division, multiple access, as well as onboard processing and switching. Thus, the quality-of-service aspects of ATM technologies are extremely important. 
ATM Quality of Service

ATM quality-of-service experiments were performed at NASA Glenn Research Center by using Moving Picture Expert Group 2 (MPEG-2), ATM application layer 5, in asynchronous transfer mode over an emulated satellite link. The purpose of these experiments was to determine the free-space link quality necessary to transmit highquality multimedia information with the ATM protocol. MPEG-2 transport streams were baselined in an errored environment before a series of tests were performed using MPEG-2 over ATM. Errors were created both digitally and in an intermediate-frequency link by using a satellite modem and a commercial Gaussian noise test set for two different MPEG-2 decoder implementations. The results show that International Telecommunications UnionTelecommunications Standards Sector (ITU-T) Recommendation I.356Class I, stringent ATM applications will require better link quality than currently specified. Specifically, cell loss ratios must be better than $1.0 \times 10^{-8}$, and cell error ratios must be better than $1.0 \times 10^{-7}$. These tests were conducted at the NASA Glenn Research Center in support of satellite-ATM interoperability research. The detailed test plan, test configurations, and results have been published. ${ }^{1}$

Quality-of-service experiments were performed by using TCP in the ATM over a synchronous optical network (SONET) to determine the necessary cell loss ratios and cell error ratios required for acceptable TCP performance. ${ }^{2}$ TCP reacts identically to cell loss and cell errors. For our experiments we used all the latest TCP enhancements, including TCP Slow Start, Congestion Avoidance, Fast Retransmit, and Fast Recovery Algorithms (request for
comment(RFC) 2001); TCPExtensions for High Performance (RFC 1323); and TCP Selective Acknowledgment Options (RFC 2018). The results indicate that a nearerror-free link is required for very large file transfers over ultra-wide band links (Fig. 1). Be careful when interpreting these data. Currently, most files transferred are relatively small such that you may never get out of slow start. Also, data passing over most wide-area networks (WAN's) consist of numerous independent flows multiplexed together. Thus, congestion dominates the network rather than errors.

\section{ATM Private Network-Node Interface}

Since its inception in the mid 1980 's asynchronous transfer mode has positioned itself as the lead networking architecture to offer a reliable method of accommodating the quality-of-service needs of voice, video, and data traffic. Because ATM is a connection-oriented technology, virtual circuits have to be established between every port and switch used in the communications path between two endpoints. In the absence of common signaling/routing protocols, this communications path would be made by manually creating permanent virtual circuits on each border node in the path, making setup and quality-ofservice changes of a circuit less attractive across large ATM networks comprising multiple equipment vendors.

In March 1996 the ATM Forum Technical Committee released document af-pnni-0055.000, The Private Network-Node Interface Specification Version 1.0(PNNI 1.0). This document serves as the basis for implementing the PNNI signaling protocol, a method of establishing switched virtual circuits across an ATM network.

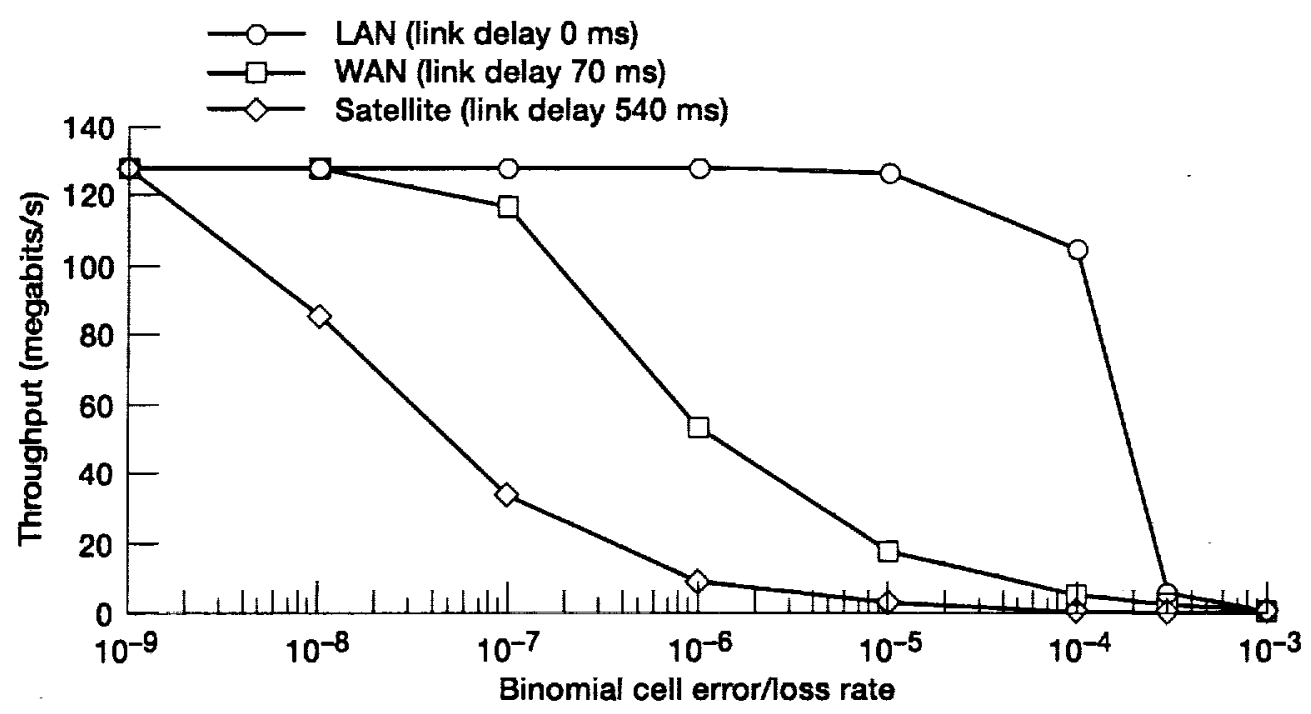

Figure 1.-Throughput versus cell error/loss rate. 
TABLE 1.-AVERAGE ABSOLLTE TIMES FOR EVENTS FOR ALL TESTS

\begin{tabular}{|l|c|c|c|c|}
\hline \multicolumn{1}{|c|}{ Test } & $\begin{array}{c}\text { Two-way } \\
\text { inside } \\
\text { achieved }\end{array}$ & $\begin{array}{c}\text { Data base } \\
\text { synchronized }\end{array}$ & $\begin{array}{c}\text { PNNI topology } \\
\text { state elements } \\
\text { exchanged }\end{array}$ & $\begin{array}{c}\text { PNNI switched } \\
\text { virtual circuit } \\
\text { created }\end{array}$ \\
\hline Control with no delay & 1.177 & 2.178 & 3.257 & 5.315 \\
Control with 250-ms delay & 1.559 & 3.067 & 4.650 & 7.163 \\
Live with no delay & 1.544 & 2.044 & 4.143 & 6.612 \\
Live with 250-ms delay & 2.059 & 3.177 & 6.151 & 9.607 \\
\hline
\end{tabular}

In addition to a signaling protocol, based on User Network Interface (UNI) 3.1, the PNNI specification also details the implementation of the PNNI routing protocol. Based loosely on the technique called open shortest path first, the PNNI routing protocol is the method of distributing the topology information, across the switches making up an ATM network, for use by the PNNI signaling protocol.

Using the PNNI Version 1.0 specification, we examined the PNNI protocols at the transaction level, learned how the protocols performed those transactions, determined a method of testing the protocols' performances, and performed tests to determine if PNNI will work correctly in a satellite or hybrid network environment, consisting of high speeds and long delays. ${ }^{3}$

In general, our results were as expected (Table 1). For two ATM switches separated by a $250-\mathrm{ms}$, one-way delay (geosynchronous satellite), the results indicate that PNNI initialization to the point where calls can be routed takes an average of $9.6 \mathrm{~s}$ versus $6.6 \mathrm{~s}$ for no delay. The average call setup times between our live network tests were 2 to $3 \mathrm{~s}$ shorter for no delay than for 250 -ms delay. It is speculated that the compounding of these delays could pose problems for hybrid networks consisting of multiple peer group nodes all connected through satellite links. Using PNNI over multiple long-delay paths might require changes to the specification to make the protocol more delay tolerant.

With regard to simpler hybrid networks the PNNI's quick initialization times show promise for low-Earthorbit (LEO) satellite applications in which an ATM switch is connected to a ground station system tracking two LEO satellites and would switch between a LEO satellite moving out of range and its successor moving into range. More importantly, the ability of PNNI to make those decisions based on factors influenced by satellite communications, such as bit error rate and cell transfer delay, would allow the change in routing from one LEO satellite to the other to take place in a timely fashion.

Although we achieved our initial objectives, our tests on PNNI were far from conclusive. Further tests could evaluate the protocol's initialization and recovery characteristics within different levels of a large PNNI hierarchy or evaluate how the protocol functions in a LEO situation, which is characterized by changing cell transfer delays and bit error rates. In addition, more interoperability tests should be performed.

\section{ATM Versus Packet-over-SONET Technology}

NASA Glenn Research Center and Cisco Systems are currently performing satellite WAN research using packetover-SONET (POS) technology. Our goals are (1) to compare ATM and POS technologies over a satellite channel to determine the overall improvements in bandwidth utilization that are obtainable by using POS instead of ATM; and (2) to determine if the quality-ofservice mechanisms available in the Internet protocol (IP) can provide similar performance to that of ATM. NASA mission planners will use this information when considering which WAN technologies to use on large space platforms, such as the space shuttle or the International Space Station.

For large IP datagrams most of the ATM penalty resides in the ATM header inefficiency. For very small IP datagrams the padding inefficiency of ATM also becomes a major factor. For example, an IP frame size of 46 bytes over an ethernet local-area network (LAN) to an OC3 WAN results in theoretical bandwidth efficiencies of 87 percent for POS and 44 percent for ATM. Obviously, this is a worst-case scenario. In general, we anticipate a bandwidth efficiency improvement of 15 to 20 percent, depending on the type of data being transmitted, for POS versus IP in ATM over SONET.

ATM is much more complex than POS and places greater processing requirements on the circuitry. In addition, for ATM application layer 5, cells from individual flows cannot be intermingled, resulting in further inefficiencies. Our testing over real equipment indicates that, for two streams of 1500-byte ethernet packets from separate 100 BaseT LAN's multiplexed over an OC3 WAN, POS provides $139 \mathrm{Mbps}$ of usable data throughput (goodput) versus a theoretical goodput of $149 \mathrm{Mbps}$ and ATM provides $113 \mathrm{Mbps}$ versus $132 \mathrm{Mbps}$ (Fig. 2).

Initial tests showed that POS has nearly identical quality-of-service mechanisms as ATM. By using IP precedence bits we were able to control the priority of various application flows. We demonstrated simultaneous transmission of voice, video, and facsimile over the same data path. We were able to control the applications priorities at the router, including available bandwidth, queuing size, and queuing strategies. 


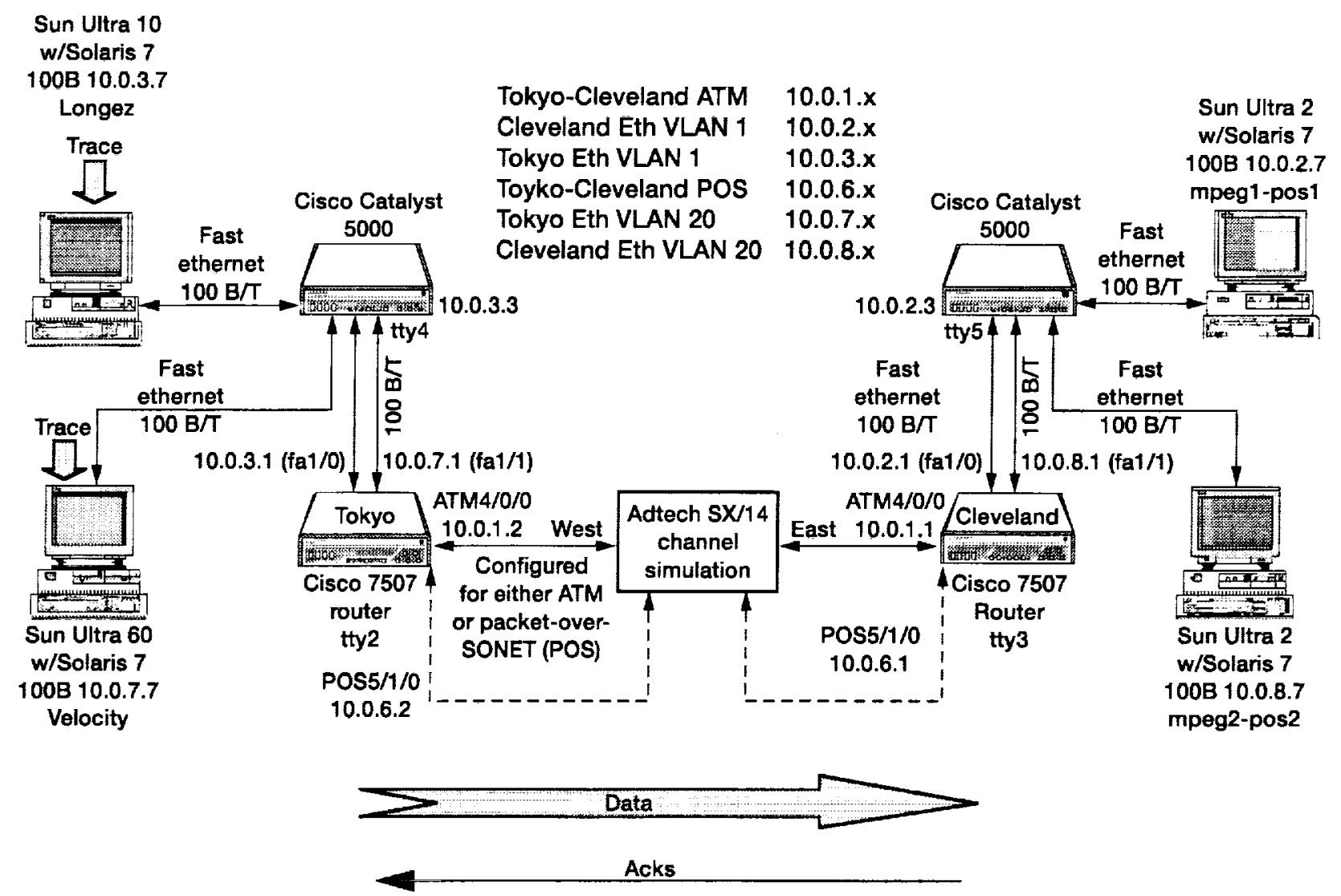

Figure 2.-Differences in test setups for asynchronous transfer mode and packet-over-SONET technology.

\begin{abstract}
$\underline{\mathrm{TCP} / \mathrm{IP}}$
Internet Engineering Task Force

The Internet is dominating communications. Satellites are continuing to address this new market. The transport control protocol/Internet protocol (TCP/IP) suite is the main group of protocols that operate over the Internet. These protocols are developed and modified by the Internet Engineering Task Force (IETF).* Working groups that have been addressing satellite-related issues include TCP Implementation (tcpimpl), TCP over Satellite (tcpsat), Performance Implications of Link Characteristics (pilc), IP Routing for Wireless/Mobile Hosts (mobileip), and Mobile ad hoc Networks (manet).
\end{abstract}

TCP Implementation working group. - The tcpimpl working group was formed in February 1997 and should be closed by the summer of 2000 . The objectives of this group were to document known TCP implementation problems and their solutions and to determine if any problems found are the result of ambiguities in the TCP

\footnotetext{
"Information on the various IETF working groups, RFC's, Internet drafts, meeting notes, and upcoming meetings are available at www ietf.org. Much of the following text is a summary or taken directly from the IETF working group web sites.
}

specification. The following requests for comment were produced with input from this working group:

1. Some Testing Tools for TCP Implementers (RFC 2398)

2. Increasing TCP's Initial Window (RFC 2414)

3. Simulation Studies of Increased Initial TCP Window Size (RFC 2415)

4. When TCP Starts Up with Four Packets into Only Three Buffers (RFC 2416)

5. Known TCP Implementation Problems (RFC 2525)

6. TCP Congestion Control (RFC 2581)

7. The NewReno Modification to TCP's Fast Recovery Algorithm (RFC 2582)

8. TCP Slow Start, Congestion Avoidance, Fast Retransmit, and Fast Recovery Algorithms (RFC 2001)

Here, the RFC's that may have the greatest effect on the satellite community are those that provide information on known implementation problems.

TCP-over-Satellite working group.-Correcting problems identified in RFC 2525, Known TCP Implementation Problems, should significantly improve performance. 
RFC's dealing with increasing TCP's initial window are of interest to the satellite community as this greatly improves the efficiency of small file transfers over longdelay links as well as reduces the amount of time that TCP is in slow start. Also, RFC 2582, The NewReno Modification to TCP's Fast Recovery Algorithm, has great potential for repairing multiple losses and hence may be of great use over satellite channels when selective acknowledgment options are not available.

In 1997, because the satellite service providers had interest in globally extending the Internet, the TCP-overSatellite working group was formed. The charter of this working group was as follows:

1. To produce informational RFC's that describe issues affecting TCP throughput over satellite links

2. To identify the domains in which each issue applies, including network topology, satellite orbit (low Earth, medium Earth, and geosynchronous), and link rates

3. To identify fixes, regarding both protocol and implementation, that ameliorate reduced throughput

4. To identify areas for further research

The last meeting of the tcpsat working group was in December 1998. All discussions concerning TCP over satellites have been moved to the Performance Implications of Link Characteristics (pilc) mailing list. However, the tcpsat mailing list is still active. The tcpsat working group produced two documents: an informational draft, Ongoing TCP Research Related to Satellites; and a Request for Comments, Enhancing TCP-over-Satellite Channels Using Standard Mechanisms (RFC 2488).

Performance Implications of Link Characteristics working group.-Although transport-layer and networklayer protocols are designed to accommodate a variety of network characteristics, particular properties of different link characteristics have a significant effect on the overall performance of Internet protocols. In December 1998 a group consisting mainly of the satellite and terrestrial wireless communities first met to discuss protocol performance issues regarding link characteristics. The pilc working group officially formed in April 1999 and is currently active. The goal of pilc is to produce informational documents regarding the effect that various link characteristics have on the performance of network and transport protocols. This working group also serves as a forum for discussing possible modifications to IETF protocols to improve performance in environments with problematic link characteristics. However, this improved performance must not be to the detriment of performance and stability in the general Internet nor undermine existing security models. Currently, no RFC's have resulted from this group. However, the following Internet drafts are available:

1. End-to-End Performance Implications of Slow Links

2. End-to-End Performance Implications of Links with Errors

3. Performance-Enhancing Proxies

4. Advice for Internet Subnetwork Designers

5. TCP Performance Implications of Network Asymmetry

Robust Header Compression working group.-As of this writing a new working group, Robust Header Compression (robhc), is forming to address those issues. The goal of the working group is to develop header compression schemes that perform well over links with high error rates and long round-trip times. The schemes must perform well for cellular links and over unidirectional links and must be applicable to other future link technologies with high losses and long round-trip times.

IPRouting for Wireless/Mobile Hosts and Mobile ad hoc Networks working groups.-Two active routing protocol working groups that address issues that should be of interest to satellite service providers are IP Routing for Wireless/Mobile Hosts (mobileip) and Mobile ad hoc Networks (manet). The mobileip working group is developing routing support to permit IP nodes (hosts and routers) to seamlessly "roam" among IP subnetworks and media types. The mobile IP method supports transparency above the IP layer, including the maintenance of active TCP connections and user datagram protocol port bindings. The working group focuses on deployment issues in mobile IP and provides appropriate protocol solutions to address known deficiencies and shortcomings.

The primary focus of the manet working group is to develop and evolve routing specifications that enable mobile self-forming networks. The goal is to support networks scaling up to hundreds of routers. A mobile ad hoc network is an autonomous system of mobile routers (and associated hosts) connected by wireless links. The routers are free to move randomly and organize themselves arbitrarily; thus, the network's wireless topology may change rapidly and unpredictably. Such a network may operate in a stand-alone fashion or may be connected to the larger Internet.

\section{TCP Research}

TCP pacing.-Recent TCP research regarding pacing has been performed by GTE/BBN under various NASAfunded contracts. ${ }^{4}$ Current implementations of TCP optimize its send rate by transmitting increasingly large bursts of packets, one burst per round-trip time, until it reaches the full capacity of the network. In networks with large delay bandwidth products, such as satellite networks, 


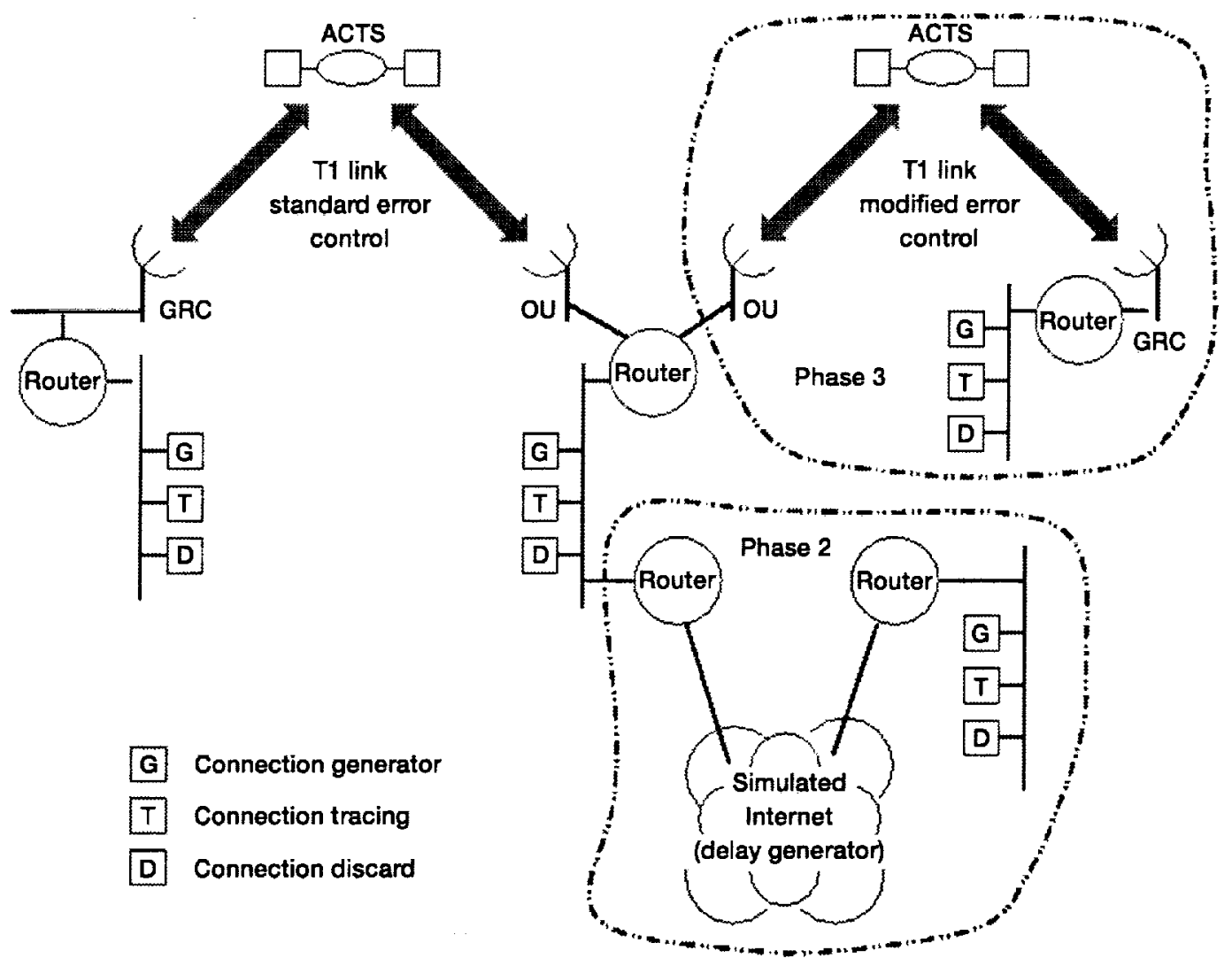

Figure 3.-Combined satellite and terrestrial network.

the maximum window size is often larger than the queue size of intermediate routers. Thus, routers will drop packets as soon as the window becomes too large for the router queues. Using paced TCP a sender would release multiple small bursts of packets over the course of one round-trip time rather that one large burst of packets. This approach allows the sender to increase the send rate to the maximum window size without encountering queuing bottlenecks. In addition, as an alternative to today's slow-start algorithm, it may be possible to estimate the overall available band width within a few round-trip times and quickly ramp up to the available bandwidth. Many issues need to be resolved with pacing TCP before it can even be considered for proposal as a standard. Much more research is required; however, the potential improvements in transport efficiency are worth pursuing.

Unidirectional link routing.-Satellites provide a unique capability to multicast and broadcast to an extremely large user base. However, the current Internet network topologies have not addressed data-link layer mapping. NASA Glenn Research Center, in cooperation with Cisco Systems, has been addressing this problem through a technique known as unidirectional link routing for unicast and multicast environments (UDLR). Traditional unicast and multicast routing protocols assume a duplex link. However, there are several satellite and other wireless network architectures where the return link may be by an alternative path. Cisco Systems has recently modified some of the layer 2 and layer 3 software routing code to accommodate such situations. The technique is known as unidirectional link routing. UDLR provides a method for forwarding data packets over a unidirectional satellite link of high bandwidth to stub networks that have a back channel. This technique is similar to stub multicast routing.

UDLR can be implemented in one of two ways. One way is to create a tunnel, which effectively allows the routing protocols to believe that the one-way link is a duplex one. The second way is a UDLR enhancement to the Internet group management protocol (IGMP). Using IP multicast routing with IGMP makes large-scale multicast routing over unidirectional links possible.

NASA has incorporated this UDLR code into a threeterminal satellite network residing at both NASA Glenn Research Center and two Cleveland Clinic facilities. This network is being used on the ACTS for telemedicine applications. 5 This new unidirectional link routing 
technology has been used to efficiently disseminate medical imagery, such as mammograms, to numerous locations simultaneously.

Multistream TCP.-Ohio University and NASA Glenn Research Center are performing joint research into TCP over satellite networks to determine the overall efficiency of the appropriate TCP extensions when realistic network traffic is transferring through a satellite network. In addition, faimess will be assessed for a combined satellite and terrestrial network (Fig. 3) where the terrestrial network has 5 to 10 times less delay relative to a geostationary satellite.

\section{AERONAUTICS}

Three aeronautics programs are currently being addressed by the Federal Aviation Administration, NASA, and other U.S. and foreign governments and industry: the Advanced Aeronautics Transportation Technology (AATT), Weather Information Communications (WINCOMM), and the Smart Aircraft Transportation System (SATS). Within AATT is a program segment for air traffic management known as free flight. The concept is to allow aircraft to fly more direct routes rather than having to stay within the current designated routes, thereby improving transportation efficiency and reducing overall cost. The WINCOMM program is directed at improving air safety by getting more and better weather-related information to the cockpit. SATS combines and expands on the efforts of both the AATT and WINCOMM programs. The concept of SATS is to off-load major airports by enabling the use of small airports, such as county airports, for air transportation routes shorter than a few hundred miles. To achieve this, intelligent aircraft have to be developed that are as easy to operate as today's automobiles. All these concepts require much greater communications capability to the aircraft than currently exists.

Satellites provide a unique capability to communicate with and provide wide-band communications to aircraft. A communications infrastructure that uses satellites will help enable such concepts as free flight as well as improve air safety through dissemination of weather and air traffic information.

Currently, the free-flight segment of AATT requires an international standard protocol known as the aeronautics telecommunications network (ATN) protocol. ATN is very similar to the TCP/P suite and was developed more than 15 years ago by enhancing the 1980's TCP/IP to include congestion control and mobility management. ATN cannot accommodate multicasting; however, AATT does not currently require multicasting. Since the development of ATN, TCP/IP has surpassed ATN in capability. Today's TCP/IP now has incorporated and globally deployed protocols that include congestion control, quality-of-service provisions, mobility management, and multicasting. The TCP/IP protocols suite is the basis for the Internet and therefore can most assuredly handle the AATT requirements in a much more costeffective manner than ATN. ${ }^{6}$

The WINCOMM program requires that weather information be distributed to numerous aircraft in a given region simultaneously. Thus, WINCOMM requires a protocol that can accommodate broadcast and multicast requirements. TCP/IP is well suited for this. Therefore, we anticipate TCP/IP to be used for weather information dissemination. In addition, we expect satellites to play a major role in this communications network because of their natural ability to provide broadcast and multicast services.

The SATS program requires cost-effective, reliable, communications services and large amounts of information. The ideal situation for SATS is to have an aircraft that will nearly fly itself. Therefore, all communications and information must be automated, including air traffic management, flight control systems, and navigation. Extending today's Internet to the aeronautics network (Aeronautics Internet) is now being discussed. TCP/PP would form the basis of this communications network.

\section{CONCLUDING REMARKS}

The asynchronous transfer mode (ATM) protocol, the transport control protocol/Internet protocol (TCP/PP), and the aeronautics communications network (ATN) protocol are currently being used to provide much of the world's communications. We anticipate that ATM and ATN technologies will be around for some time. However, we speculate that the TCP/IP protocols suite will dominate and may eventually replace ATN and much of ATM because this widely deployed, continually evolving set of protocols is easy to use and cost effective.

As the world becomes more technologically advanced, the need for better and more communications grows dramatically. Satellites are an efficient means of providing global connectivity, and their use is expected to grow in many areas-particularly for applications requiring mobility, multicasting, and broadcasting.

\section{REFERENCES}

1. W.D. Ivancic, B.D. Frantz, and M.J. Spells: MPEG2 over Asynchronous Transfer Mode (ATM) over Satellite Quality of Service (QoS) Experiments: Laboratory Tests, NASA/TM-1998-206535, 1998.

2. B.D. Frantzand W.D. Ivancic: ATM QoS Experiments Using TCP Applications: Performance of TCP/PP over ATM in a Variety of Errored Links, NASA/ TM-1999-209644, 1999. 
3. R. Dimond: PNNI Performance Validation Test Report, NASA/CR-1999-209412, 1999.

4. J. Kulik, R. Coulter, D. Rockwell, and C. Partridge: A Simulation Study of Paced TCP, NASA/CR-2000209416, 2000.
5. R. Kerczewski, et al.: Advanced Satellite Communications Technology for Efficient, Low-Cost Teleradiology, Proceedings of the Global Telemedicine and Federal Technologies Symposium, 1998.

6. C. Dhas, et al: Aeronautical Related Applications Using ATN and TCP/IP, NASA/CR - 2000-209922. 


\begin{tabular}{|c|c|c|c|}
\hline \multicolumn{3}{|c|}{ REPORT DOCUMENTATION PAGE } & $\begin{array}{l}\text { Form Approved } \\
\text { OMB No. 0704-0188 }\end{array}$ \\
\hline \multicolumn{4}{|c|}{ 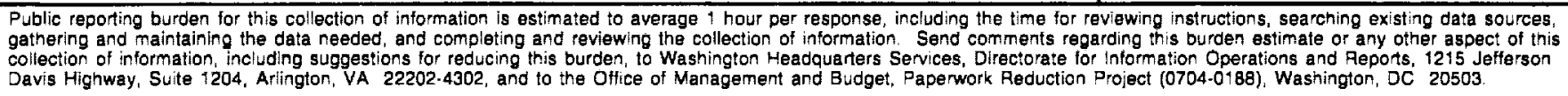 } \\
\hline 1. AGENCY USE ONLY (Leave blank) & $\begin{array}{r}\text { 2. REPORT DATE } \\
\text { February } 2000\end{array}$ & 3. REPORT TYPE A & $\begin{array}{l}\text { ND DATES COVERED } \\
\text { Technical Memorandum }\end{array}$ \\
\hline \multicolumn{3}{|c|}{$\begin{array}{l}\text { 4. TITLE AND SUBTITLE } \\
\text { Satellite Communications Using Commercial Protocols }\end{array}$} & \multirow{2}{*}{$\begin{array}{l}\text { 5. FUNDING NUMBERS } \\
\text { WU-632-6E-51-00 }\end{array}$} \\
\hline \multicolumn{3}{|c|}{$\begin{array}{l}\text { 6. AUTHOA(S) } \\
\text { William D. Ivancic, James H. Griner, Robert Dimond, Brian D. Frantz } \\
\text { Brian Kachmar, and Dan Shell }\end{array}$} & \\
\hline \multicolumn{3}{|c|}{$\begin{array}{l}\text { 7. PERFORMING ORGANIZATION NAME(S) AND ADDRESS(ES) } \\
\text { National Aeronautics and Space Administration } \\
\text { John H. Glenn Research Center at Lewis Field } \\
\text { Cleveland, Ohio } 44135-3191\end{array}$} & $\begin{array}{l}\text { 8. PERFORMING ORGANIZATION } \\
\text { REPORT NUMBER }\end{array}$ \\
\hline \multicolumn{3}{|c|}{$\begin{array}{l}\text { 9. SPONSORING/MONITORING AGENCY NAME(S) AND ADDRESS(ES) } \\
\text { National Aeronautics and Space Administration } \\
\text { Washington, DC 20546-0001 }\end{array}$} & $\begin{array}{l}\text { 10. SPONSORING/MONITORING } \\
\text { AGENCY REPORT NUMBER } \\
\text { NASA TM-2000-209796 } \\
\text { AIAA-2000-1185 }\end{array}$ \\
\hline \multicolumn{4}{|c|}{$\begin{array}{l}\text { 11. SUPPLEMENTARY NOTES } \\
\text { Prepared for the } 18 \text { th International Communication Satellite Systems Conference sponsored by the American Institute of Aeronautics and Astronautics, } \\
\text { Oakland, California, April 10-14, 2000. William D. Ivancic and James H. Griner, NASA Glenn Research Center; Robert Dimond and Brian D. Frantz, } \\
\text { BBN Technologies, GTE Internetworking, 10 Moulton Street, Cambridge, Massachusetts 02138; Brian Kachmar, Analex Corporation, } 3001 \text { Aerospace } \\
\text { Parkway, Brook Park, Ohio 44142; Dan Shell, Cisco Systems, Incorporated, } 170 \text { West Tasman Drive, San Jose, California 95134. Responsible person, } \\
\text { William D. Ivancic, organization code 5610, (216) 433-3494. }\end{array}$} \\
\hline \multicolumn{3}{|c|}{$\begin{array}{l}\text { 12a. DISTRIBUTION/AVAILABILITY STATEMENT } \\
\text { Unclassified - Unlimited } \\
\text { Subject Category: } 17 \\
\text { This publication is available from the NASA Center for AeroSpace Information, (301) } 621-0390 \\
\end{array}$} & 12b. DISTRIBUTION CODE \\
\hline
\end{tabular}

13. ABSTRACT (Maximum 200 words)

NASA Glenn Research Center has been working with industry, academia, and other government agencies in assessing commercial communications protocols for satellite and space-based applications. In addition, NASA Glenn has been developing and advocating new satellite-friendly modifications to existing communications protocol standards. This paper summarizes recent research into the applicability of various commercial standard protocols for use over satellite and spacebased communications networks as well as expectations for future protocol development. It serves as a reference point from which the detailed work can be readily accessed. Areas that will be addressed include asynchronous-transfer-mode quality of service; completed and ongoing work of the Internet Engineering Task Force; data-link-layer protocol development for unidirectional link routing; and protocols for aeronautical applications, including mobile Internet protocol routing for wireless/mobile hosts and the aeronautical telecommunications network protocol.

\begin{tabular}{|c|c|c|}
\hline \multicolumn{3}{|l|}{ 14. SUBJECT TERMS } \\
\hline $\begin{array}{l}\text { 17. SECURITY CLASSIFICATION } \\
\text { OF REPORT } \\
\text { Unclassified }\end{array}$ & $\begin{array}{l}\text { 18. SECURITY CLASSIFICATION } \\
\text { OF THIS PAGE } \\
\text { Unclassified }\end{array}$ & $\begin{array}{l}\text { 19. SECURITY CLASSIFICATION } \\
\text { OF ABSTRACT } \\
\text { Unclassified }\end{array}$ \\
\hline
\end{tabular}

